\title{
Redistribution of adrenomedullary nicotinic acetylcholine receptor subunits and the effect on circulating epinephrine levels in a murine model of acute asthma
}

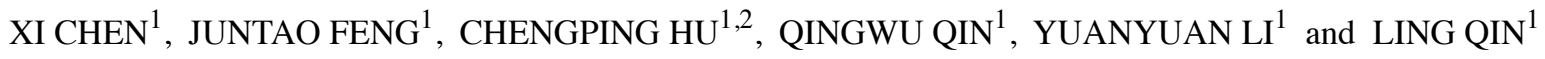 \\ ${ }^{1}$ Department of Respiratory Medicine, Xiangya Hospital, Central South University (Key Site of the \\ National Clinical Research Center for Respiratory Disease); ${ }^{2}$ Bronchial Asthma Research Center \\ of Hunan, Changsha, Hunan 410008, P.R. China
}

Received December 21, 2015; Accepted December 16, 2016

DOI: $10.3892 / \mathrm{ijmm} .2016 .2836$

\begin{abstract}
The lack of circulating epinephrine (EPI) in the pathogenesis of asthma has long been attributed to the lack of adrenergic nerves in human airways. However, in this study we considered that EPI levels are regulated by EPI release in addition to synthesis. Nicotinic acetylcholine receptors (nAChRs) have been shown to control EPI release, and we hypothesized that redistribution of $\mathrm{nAChR}$ subunits modulates EPI release and circulating EPI levels. Using a mouse model of asthma, circulating EPI levels were measured by enzyme-linked immunosorbent assays. Changes in the expression of $\mathrm{nAChR}$ subunits in the adrenal medulla were observed by reverse transcription-quantitative polymerase chain reaction (RT-qPCR) and western blot analysis. Expression of phenylethanolamine $\mathrm{N}$-methyltransferase, tyrosine hydroxylase and galanin was detected by RT-qPCR. Lung pathology, airway resistance (RL) and EPI levels were also assessed after treatment with an $\alpha 7 \mathrm{nAChR}$ agonist or antagonist. $\alpha 7 \mathrm{nAChR}$ mRNA expression in the adrenal medulla was increased by more than 2-fold $(\mathrm{P}<0.05)$, and circulating EPI levels increased rapidly after treatment with the $\alpha 7 \mathrm{nAChR}$ agonist. These results indicated that increased EPI release, which was caused by the overexpression of $\alpha 7 \mathrm{nAChR}$, was responsible for elevated circulating EPI levels. After treatment with an agonist of $\alpha 7 \mathrm{nAChR}$, RL was significantly decreased. Serum corticosterone levels in individual mice were measured to rule out glucocorticoid as the main mediator of changes in EPI levels. On the whole, redistribution of $\mathrm{nAChR}$ subunits, primarily $\alpha 7 \mathrm{nAChR}$, occurs in the adrenal medulla in asthmatic mice. Increased $\alpha 7 \mathrm{nAChR}$
\end{abstract}

Correspondence to: Professor Chengping $\mathrm{Hu}$, Department of Respiratory Medicine, Xiangya Hospital, Central South University, 88 Xiangya Road, Changsha, Hunan 410008, P.R. China

E-mail: huchengp28@126.com

Key words: epinephrine release, $\alpha 7$ nicotinic acetylcholine receptor, asthma, adrenal medulla expression can rapidly increase serum EPI levels and decrease airway responsiveness.

\section{Introduction}

Inhaled $\beta 2$-adrenoceptor agonists are among the most effective and safest bronchodilators currently available. Epinephrine (EPI), a $\beta 2$-adrenergic receptor agonist, relaxes bronchial smooth muscle and is used widely to treat asthma. Endogenous EPI levels are low in patients with asthma, which may explain why EPI delivery is such an effective treatment $(1,2)$. In our previous studies involving the induction of adrenal medullary chromaffin cell (AMCC) transformation into neurons, we observed decreased EPI levels and found that this phenomenon was inhibited by administration of the anti-nerve growth factor (anti-NGF) antibody $(3,4)$. Thus, transformation of AMCCs into neurons reduces EPI synthesis and induces bronchoconstriction in asthma, with reduced phenylethanolamine N-methyltransferase (PNMT) expression in the neurons. Of course, both EPI synthesis and release determine serum EPI concentrations, and little is currently known concerning EPI release in asthma patients.

The adrenomedullary hormonal system plays an important role in the regulation of bronchial dilatation via secretion of EPI (5). At the adrenomedullary synapses, neuron terminals release the classical transmitter acetylcholine. Acetylcholine interacts with nicotinic acetylcholine receptors (nAChRs) on the adrenal medulla to induce elevation of the intracellular calcium concentration $\left(\left[\mathrm{Ca}^{2+}\right]_{\mathrm{i}}\right)(6)$ and then secretion of EPI (7). In this process, the $\left[\mathrm{Ca}^{2+}\right]_{\mathrm{i}}$ directly influences EPI secretion from the adrenal medulla, and the $\left[\mathrm{Ca}^{2+}\right]_{\mathrm{i}}$ is dependent on the regulation of nAChRs. Pentameric combinations of homologous $n A C h R s$ are formed by the $\alpha 2-10$ and $\beta 2-4$ subunits, and differential associations of these subunits confer distinct functional and structural properties $(6,8)$. Heteromeric nAChRs consisting of $\alpha$ - and $\beta$-subunits have a fractional $\mathrm{Ca}^{2+}$ current (7), whereas nAChRs containing the $\alpha 7$ subunit have the highest fractional $\mathrm{Ca}^{2+}$ current among all nAChRs (9).

Redistribution of $\mathrm{nAChR}$ subunits in PC12 cells in response to exposure to nicotine, NGF and hypoxia has been demonstrated within only a couple of hours following 
treatment (9-11). The redistribution did not change the total number of receptors, but instead changed the proportions of different receptor subunits (12). Based on these previous demonstrations of $\mathrm{nAChR}$ subunit redistribution and increased expression of the $\alpha 7 \mathrm{nAChR}$ subunit in neuronal cells exposed to various stress $(9,11)$, we hypothesized that redistribution of adrenomedullary $\mathrm{nAChRs}$ occurs in asthma, with increased expression of the $\alpha 7$ subunit, and that this phenomenon influences EPI secretion. To test this hypothesis, we employed a mouse model of ovalbumin (OVA)-induced asthma to determine whether the adrenal medulla of these mice exhibits redistribution of $n A C h R s$. We then investigated the effects of an agonist and an antagonist of the $\alpha 7 \mathrm{nAChR}$ subunit on EPI secretion and asthma symptoms in mice with asthma.

\section{Materials and methods}

Animals and treatments. Conventionally bred 6- to 8-week-old female C57BL/6 mice (Experimental Animal Center of Central South University, Changsha, China) were used in all animal experiments. This study was carried out in strict accordance with the recommendations from the Guide for the Care and Use of Laboratory Animals published by the National Institutes of Health (Bethesda, MD, USA). The study protocol was approved by the Ethics Committee of the Asthma Research Institute (Hunan, China) (20100606).

For the first set of experiments, 32 mice were divided among the following 4 groups ( $n=8 /$ group) using a random number table: a control group injected with saline (control group); a control group treated with anti-NGF only (anti-NGF group); a group sensitized by chicken OVA (asthma group); and a group sensitized by OVA and treated with anti-NGF (asthma + anti-NGF group). The mice in the asthma group and asthma + anti-NGF group were sensitized intraperitoneally (i.p.) with $0.2 \mathrm{ml}$ of a mixture containing $50 \mu \mathrm{g}$ OVA (grade V) and $2 \mathrm{mg}$ aluminum hydroxide (Sigma-Aldrich, St. Louis, MO, USA) in sterile saline on days 1 and 14. Beginning on day 21, the asthma group and asthma + anti-NGF group were exposed to $1 \%$ OVA (w/v) aerosol for 30 min every day from day 21 to 23 and treated with $1.0 \mathrm{mg} / \mathrm{kg}$ anti-NGF (i.p.) for $60 \mathrm{~min}$ before each aerosol treatment. The control group and anti-NGF group received aerosol treatment with sterile saline only.

For the second set of experiments, 240 mice were divided into two groups ( $n=120 /$ group) using a random number table: an original control group injected with saline (control $\mathrm{O}$ group); and a group sensitized with OVA (OVA group). The mice in the OVA group were sensitized i.p. with $0.2 \mathrm{ml}$ of a mixture of $50 \mu \mathrm{g}$ OVA (grade $\mathrm{V}$ ) and $2 \mathrm{mg}$ aluminum hydroxide in sterile saline on days 1 and 14. Beginning on day 21 , the OVA group was exposed to $1 \%$ OVA (w/v) aerosol for 30 min every day from day 21 to 23 . The control $\mathrm{O}$ group received aerosol treatment with sterile saline only. Then the OVA group and the control $\mathrm{O}$ group were divided into three subgroups ( $\mathrm{n}=40 /$ group) each using a random number table. Mice in the OVA group were divided into: i) a group sensitized with OVA and treated with methyllycaconitine (MLA; Sigma-Aldrich) (asthma + MLA group); ii) a group sensitized with OVA and given saline (asthma + saline group); and iii) a group sensitized with OVA and treated with PNU-282987 (Sigma-Aldrich) (asthma + PNU group). Mice in the control O group were divided into: iv) a control group given saline only (control 2 group); v) a group treated with MLA but not sensitized with OVA (MLA group); and vi) a group treated with PNU-282987 but not sensitized with OVA (PNU group). Mice were treated with MLA or PNU-282987 at 30 min after the last aerosol treatment, and then we measured bronchial responsiveness of the mice chosen using a random number table. At the same time, we sacrificed five mice in each group at 30, 35, 40, 45, 50, 55 and $60 \mathrm{~min}$ after MLA or PNU-282987 treatment ( 5 mice per group per time selected using a random number table), because excessive blood draws would interfere with the experiment.

Measurement of bronchial responsiveness. The airway responsiveness to methacholine was measured at $1 \mathrm{~h}$ after the final OVA challenge using a whole-body plethysmography device (model PLY 3211; Buxco Electronics, Inc., Wilmington, $\mathrm{NC}$, USA). The airway resistance (RL) of individual mice was calculated by dividing the driving pressure by the rate of air flow $(\mathrm{P} / \mathrm{V})$. We injected $10 \mathrm{mg} / \mathrm{kg}$ MLA i.p. into mice in the asthma + MLA and MLA groups, $0.4 \mathrm{mg} / \mathrm{kg}$ PNU-282987 i.p. into mice in the asthma + PNU and PNU groups, and saline into mice in the asthma + saline group and the control 2 group $30 \mathrm{~min}$ before measurement of bronchial responsiveness. After measuring airway responsiveness, blood samples were collected by cardiac puncture, and the mice were sacrificed.

Histological analysis. Lung tissues were collected, fixed in $4 \%$ paraformaldehyde, and then embedded in paraffin. Tissue sections $(4 \mu \mathrm{m})$ were stained with hematoxylin and eosin (H\&E), and morphological changes were observed via light microscopy. Inflammatory parameters in lung tissue (peribronchial, perivascular and parenchymal infiltration of inflammatory cells) were evaluated in a blinded manner by a senior lung pathologist.

Reverse transcription-quantitative-polymerase chain reaction (RT-qPCR) analysis. Total RNA from the adrenal medulla of mice was extracted using TRIzol reagent and the SuperScript ${ }^{\mathrm{TM}}$ total RNA isolation kit (both from Invitrogen, Carlsbad, CA, USA), according to the manufacturer's instructions. The mRNA levels of target gene transcripts and $\beta$-actin, as an internal control, were determined by quantitative PCR using the SYBR-Green PCR kit in a 7900HR Fast Real-Time PCR system (Bio-Rad Laboratories, Inc., Hercules, CA, USA). The primer sequences used are listed in Table I. The PCR amplification was performed at $95^{\circ} \mathrm{C}$ for 5 min then 42 cycles of $95^{\circ} \mathrm{C}$ for $30 \mathrm{sec}$ plus $59^{\circ} \mathrm{C}$ for $30 \mathrm{sec}$, followed by $72^{\circ} \mathrm{C}$ for $20 \mathrm{sec}$ and $95^{\circ} \mathrm{C}$ for $10 \mathrm{sec}$. The relative mRNA expression levels of each target gene transcript compared to those of the control $\beta$-actin were analyzed by the $2^{-\Delta \Delta \mathrm{Ct}}$ method.

Western blot analysis. Following homogenization and quantification, the protein lysates from mouse adrenal medulla (30 $\mu \mathrm{g} /$ lane) were loaded on $8 \%$ sodium dodecyl sulfate-polyacrylamide gel electrophoresis (SDS-PAGE) gels and then transferred onto polyvinylidene fluoride (PVDF) membranes (Millipore, Billerica, MA, USA). The membranes were blocked with $0.05 \mathrm{~g} / \mathrm{ml}$ skim milk at room temperature for $2 \mathrm{~h}$ before incubation with the primary anti- $\alpha 7$ 
Table I. Primer sequences.

\begin{tabular}{|c|c|c|}
\hline Primers & Sequences $\left(5^{\prime} \rightarrow 3^{\prime}\right)$ & $\begin{array}{l}\text { Amplicon } \\
\text { length (bp) }\end{array}$ \\
\hline nAChR- $\alpha 3-F$ & GCTAGCTTAGCTGTGCTTCG & 71 \\
\hline$n A C h R-\alpha 3-R$ & GTCTGAAGACCGCATGGACA & \\
\hline nAChR- $\alpha 4-\mathrm{F}$ & AGTCGAGACCCAGCCTACAT & 81 \\
\hline nAChR- $\alpha 4-\mathrm{R}$ & GGACTGGCCTTCTCAACCTC & \\
\hline $\mathrm{nAChR}-\alpha 5-\mathrm{F}$ & TTACAATGCCAAGTGATGAC & 124 \\
\hline $\mathrm{nAChR}-\alpha 5-\mathrm{R}$ & GAGGACTCTGAAGGACAAC & \\
\hline nAChR- $\alpha 6-F$ & CTGCGTCACATCTGGAAG & 185 \\
\hline nAChR- $\alpha 6-\mathrm{R}$ & GTTATCACACCGTCATACTTG & \\
\hline $\mathrm{nAChR}-\alpha 7-\mathrm{F}$ & GTCACCTACACAGTAACCAT & 109 \\
\hline $\mathrm{nAChR}-\alpha 7-\mathrm{R}$ & CAGGCAGCAAGAATACCA & \\
\hline nAChR- $\alpha 9-F$ & ATTGTCAACCTCCTCATCC & 146 \\
\hline nAChR- $\alpha 9-\mathrm{R}$ & ATCTCTGCCACCATTAGC & \\
\hline $\mathrm{nAChR}-\beta 2-\mathrm{F}$ & ACTTGTGTTCCCTAGAAGAGCAG & 284 \\
\hline $\mathrm{nAChR}-\beta 2-\mathrm{R}$ & TGTCAGTACCCAAAACCCCTG & \\
\hline $\mathrm{nAChR}-\beta 4-\mathrm{F}$ & CACCTCСCTTGACATTCCCC & 135 \\
\hline nAChR- $\beta 4-R$ & CAGGATGCCATGGTGTGAGT & \\
\hline GAL-F & GCCCACATGCCATTGACAAC & 140 \\
\hline GAL-R & GCGGACAATGTTGCTCTCAG & \\
\hline PNMT-F & GTGTCGGGACGGGTTCTCAT & 120 \\
\hline PNMT-R & GTGTCGGGACGGGTTCTCAT & \\
\hline $\mathrm{TH}-\mathrm{F}$ & GTCTACTGTCTGCCCGTGAT & 180 \\
\hline TH-R & CAATGTCCTGGGAGAACTGG & \\
\hline GAPDH-F & AGGAGCGAGACCCCACTAAC & 87 \\
\hline GAPDH-R & CGGAGATGATGACCCTTTTG & \\
\hline
\end{tabular}

nAChR, nicotinic acetylcholine receptor; GAL, galanin; TH, tyrosine hydroxylase; PNMT, phenylethanolamine N-methyltransferase; F, forward; $\mathrm{R}$, reverse.

nAChR antibody (1:1,000; ab10096; Abcam, Cambridge, MA, USA) and primary anti- $\beta$-actin antibody $(1: 1,000$; AM1021B; Abgent, Inc., San Diego, CA, USA) overnight at $4^{\circ} \mathrm{C}$. Protein levels were detected via incubation with horseradish peroxidase (HRP)-conjugated secondary antibodies (goat anti-rabbit IgG/HRP; dilution 1:5,000; 074-1506; KPL, Gaithersburg, MD, USA) and visualized using enhanced chemiluminescence detection. The relative protein expression levels and/or phosphorylation levels of target proteins were determined by intensity analysis using Image Pro-Plus 6.0 software (IPP 6.0; Media Cybernetics, Inc., Rockville, MD, USA).

Enzyme-linked immunosorbent assay (ELISA). EPI and corticosterone protein levels in serum of the mouse models were quantified using commercial ELISA kits (Abnova, Taipei, Taiwan), following the manufacturer's instructions. The intensities were measured at $450 \mathrm{~nm}$ using a spectrometer (Thermo Fisher Scientific, Inc., Waltham, MA, USA), and the concentrations of target proteins were calculated and analyzed. We injected $10 \mathrm{mg} / \mathrm{kg}$ MLA i.p. into mice in the asthma + MLA group and MLA group, $0.4 \mathrm{mg} / \mathrm{kg}$ PNU-282987 i.p. into mice in the asthma + PNU group and PNU group, and saline into mice in the asthma + saline group and the control 2 group. We then
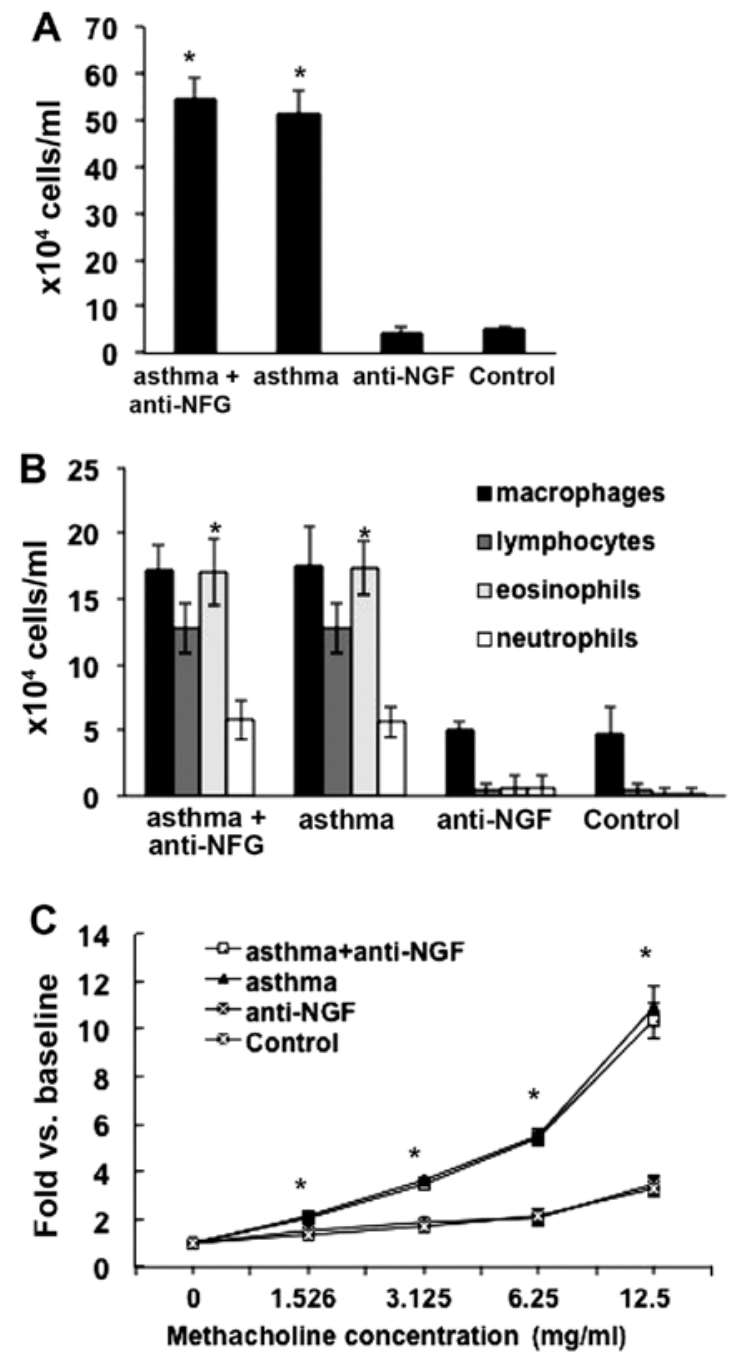

Figure 1. Cell counts in bronchoalveolar lavage fluid and airway resistance assay. (A) Total cell counts and (B) differential cell counts in bronchoalveolar lavage fluid. (C) Changes in mouse airway resistance (RL) in response to increasing concentrations of methacholine. Data are expressed as fold changes of baseline (saline-induced RL) and are presented as the means \pm SD $(n=5)$. ${ }^{*} \mathrm{P}<0.05$ vs. the control group.

sacrificed five mice at 30, 35, 40, 45, 50, 55 and 60 min (5 mice per group per time selected using a random number table).

Statistical analysis. Data are presented as the means \pm standard deviation (SD) values. One-way analysis of variance (ANOVA) was used for multiple comparisons, followed by the Fisher's protected least significant difference test. A P-value $<0.05$ was considered statistically significant.

\section{Results}

$\alpha 7 n A C h R$ expression is enhanced in the asthma group. Compared to that in the control group, the total white cell counts in the bronchoalveolar lavage fluid from mice in the asthma and asthma + anti-NGF groups were significantly increased $(\mathrm{P}<0.05)$, and eosinophil counts were also significantly increased ( $\mathrm{P}<0.05$; Fig. $1 \mathrm{~A}$ and $\mathrm{B})$. As shown in Fig. $1 \mathrm{C}$, $\mathrm{RL}$ measurements in the asthma and asthma + anti-NGF groups were significantly higher than those in the control group $(\mathrm{P}<0.05)$ in response to methacholine at a concentration 


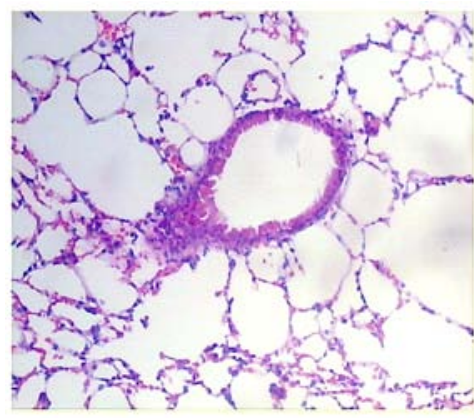

Control

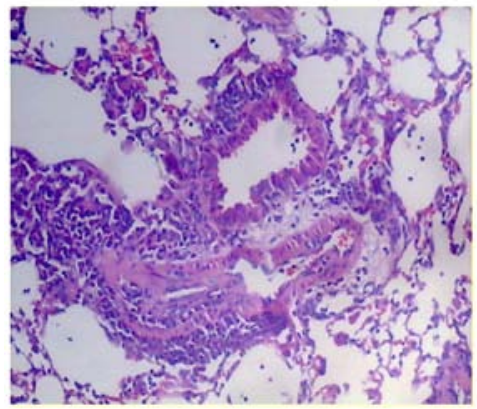

asthma+anti-NGF

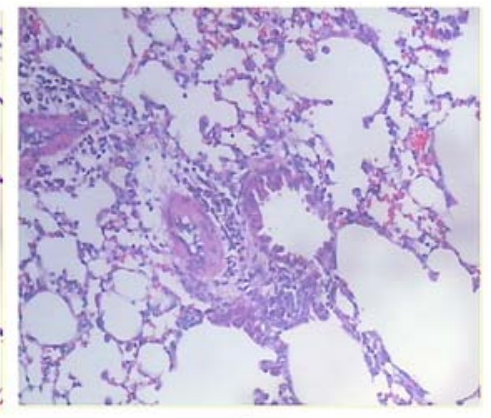

asthma

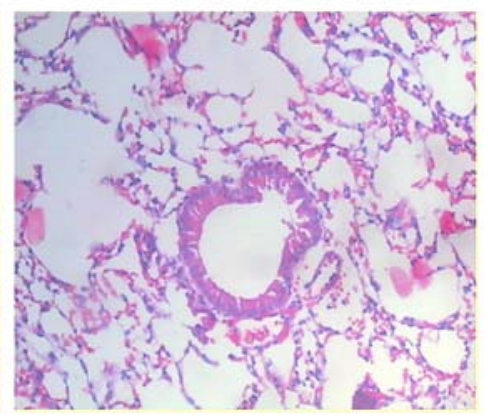

anti-NGF

Figure 2. Lung inflammatory reactions. No obvious inflammation, bronchial smooth muscle thickening, or airway mucus was observed in lung tissues of the control group and anti-NGF group. Bronchial epithelial shedding and eosinophil and neutrophil infiltration surrounding the airway were observed in the asthma and asthma + anti-NGF groups. Magnification, x100.

of $1.526 \mathrm{mg} / \mathrm{ml}$ or higher. In addition, as the concentration of methacholine increased, the increase in RL became greater. RL measurements in the asthma and asthma + anti-NGF groups did not differ significantly $(\mathrm{P}>0.05)$. However, no significant differences in cell counts were observed between the asthma and asthma + anti-NGF groups ( $\mathrm{P}>0.05)$. As shown in Fig. 2, no obvious inflammation, bronchial smooth muscle thickening, or airway mucus were observed in lung tissue of the control group. In contrast, the asthma group and asthma + anti-NGF group displayed considerable muscle thickening, epithelial edema, and inflammatory cell infiltration. There were no obvious difference in epithelial edema and inflammatory cell infiltration between the asthma group and the asthma + anti-NGF group. Together, these results demonstrate that we successfully generated a mouse model of asthma.

Next we measured serum EPI concentrations by ELISA. As shown in Fig. 3, EPI concentrations did not differ between the asthma group and the control group ( $P>0.05)$. Since the body needs much higher than normal levels of EPI to cope with asthma symptoms (2), the similar EPI levels in these groups indicate an obvious insufficiency in the OVA group.

Using the established asthma model, we first evaluated the redistribution of adrenomedullary $\mathrm{nAChR}$ subunits in mice of the asthma group by assessing the expression of all possible subunits including $\alpha 3-9$ and $\beta 3-5$ (13). As shown in Fig. 4A, the relative expression level of the $\alpha 7 \mathrm{nAChR}$ subunit in the asthma group was significantly higher than that in the control group $(\mathrm{P}<0.05)$, which demonstrates that $\mathrm{nAChR}$ subunit redistribution occurred in the asthmatic mice. The results also showed that the $\alpha 7 \mathrm{nAChR}$ subunit was associated with major changes in distribution. The relative level of $\alpha 7 \mathrm{nAChR}$ expression was 2 .6-fold higher after the induction of asthma

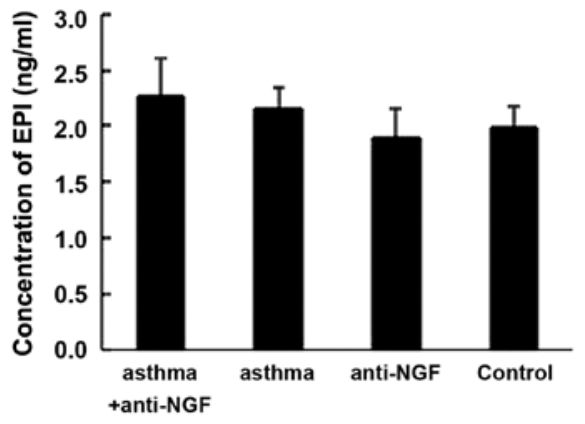

Figure 3. Serum levels of EPI in mice with asthma. The levels of serum epinephrine (EPI) in individual mice were measured by enzyme-linked immunosorbent assay (ELISA). There were no significant differences between the groups. Data are expressed as the means \pm SD of individual groups of mice ( $n=5 /$ group).

in these mice. Interestingly, the levels of $\alpha 3, \alpha 4$ and $\beta 4$ subunits in the asthma group were also relatively enhanced by 69 , 66 and 39\%, respectively. We next confirmed our findings by western blot analysis. We measured the concentration of $\alpha 7 \mathrm{nAChR}$ protein in each group separately, as shown in Fig. 4B and C, and the expression of $\alpha 7 \mathrm{nAChRs}$ in the asthma group was significantly higher than that in the control group, consistent with the results of our PCR analysis. We further measured enzymes involved in the synthesis of catecholamine (CA) such as tyrosine hydroxylase (TH), PNMT, and a neuropeptide referred to as galanin (GAL) to show that CA synthesis was not related to the nAChR distribution $(14,15)$.

Effects of agonists and antagonists of $\alpha 7 n A C h R$ on mice with asthma. To investigate the effect of $\alpha 7 \mathrm{nAChR}$ overexpression 

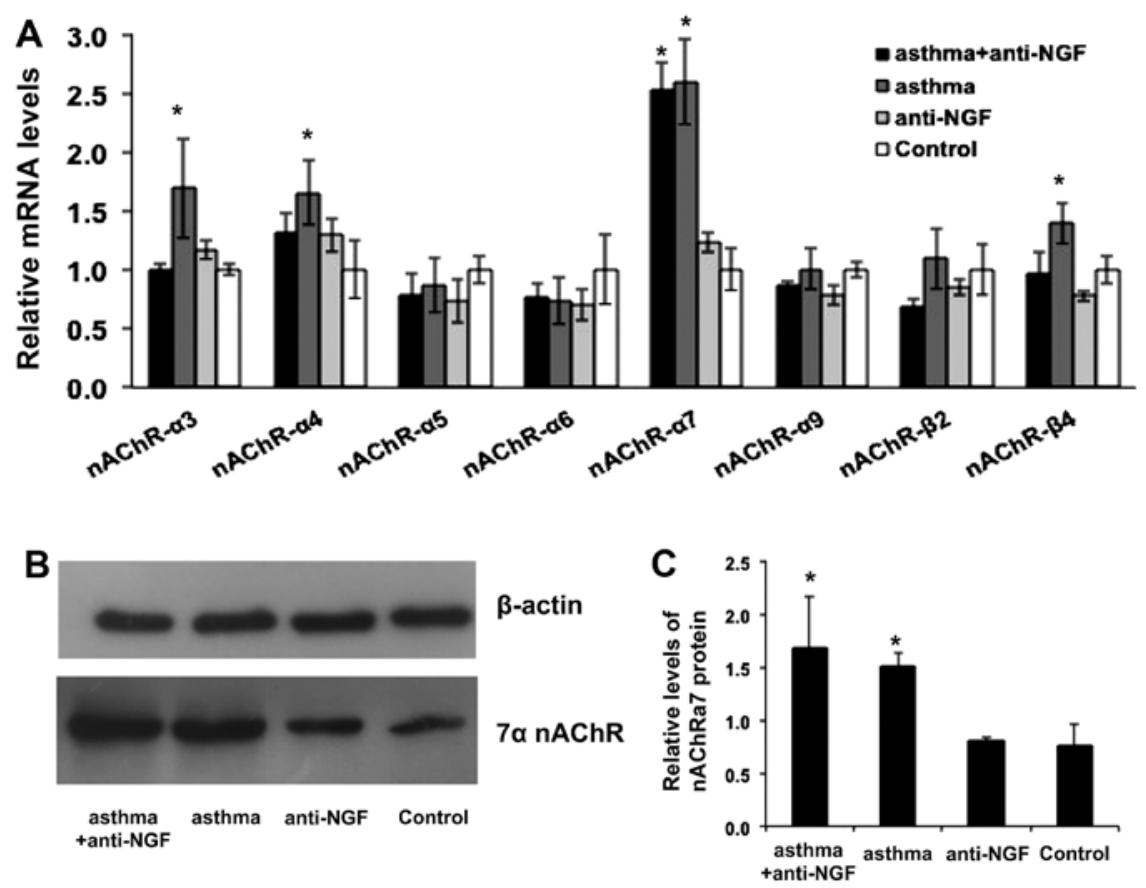

Figure 4. Nicotinic acetylcholine receptor (nAChR) expression in the adrenal medulla of mice with asthma. The relative levels of nAChR mRNAs in the adrenal medulla of individual mice were analyzed by real-time qPCR, and the relative levels of $\alpha 7 \mathrm{nAChR}$ protein in the adrenal medulla were characterized by western blot analysis. Data are expressed as the mean \pm SD for individual groups (n=5/group). (A) The relative level of $\alpha 7 \mathrm{nAChR}$ expression was $\sim 2.6$-fold higher after induction of asthma. The levels of $\alpha 3,4$, and $\beta 4 \mathrm{nAChRs}$ in the asthma group were also relatively enhanced, which were increased by 69,66 and 39\%, respectively. (B and C) Western blot analysis of the levels of $\alpha 7 \mathrm{nAChR}$ in adrenal medullary tissues of mice with asthma. The expression of $\alpha 7 \mathrm{nAChRs}$ in the asthma group was significantly higher than that in the control group. ${ }^{*} \mathrm{P}<0.05$ vs. the control group.
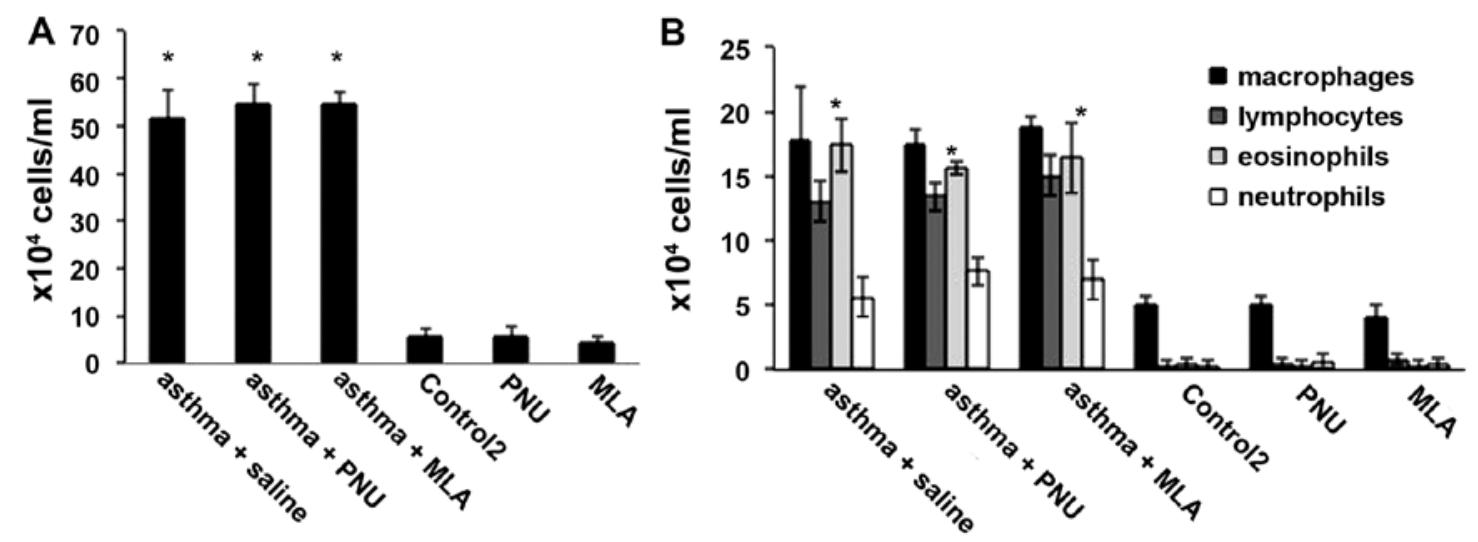

Figure 5. Cell counts in bronchoalveolar lavage fluid. (A) Total cell counts and (B) differential cell counts in bronchoalveolar lavage fluid. Data are are presented as the means $\pm \mathrm{SD}(\mathrm{n}=5)$. ${ }^{*} \mathrm{P}<0.05$ vs. the control2 group. PNU, nAChR agonist; MLA, nAChR antagonist.

on circulating EPI levels in mice with asthma, our mouse asthmatic model was treated with the $\alpha 7 \mathrm{nAChR}$ agonist PNU or the $\alpha 7 \mathrm{nAChR}$ antagonist MLA, individually $30 \mathrm{~min}$ before evaluation. First, as shown in Fig. 5A and B, compared to that in the control 2 group, the total white cell counts in bronchoalveolar lavage fluid from mice in the asthma + saline, asthma + MLA, and asthma + PNU groups were significantly increased $(\mathrm{P}<0.05)$, and eosinophil counts showed significant increases in these groups $(\mathrm{P}<0.05)$. The results in Fig. 6 show that, similar to the asthma group and control group in the previous experiments, the control 2, PNU, and MLA groups showed no obvious inflammation, bronchial smooth muscle thickening, or airway mucus in the lung tissues. In contrast, all groups sensitized with OVA (asthma + saline, asthma + MLA, and asthma + PNU groups) displayed considerable muscle thickening, epithelial edema, and inflammatory cell infiltration. Compared to the asthma + saline group, the asthma + PNU group that was treated with the $\alpha 7 \mathrm{nAChR}$ agonist exhibited less leukocyte infiltration and no significant bronchial epithelial swelling. Compared to those for the asthma + saline group, the histology results for the asthma + MLA group (treated with the $\alpha 7 \mathrm{nAChR}$ antagonist) were similar. However, compared to the asthma + PNU group, there was obvious leukocyte infiltration around the bronchus and pulmonary vessel as well as epithelial swelling in the asthma + MLA group. 


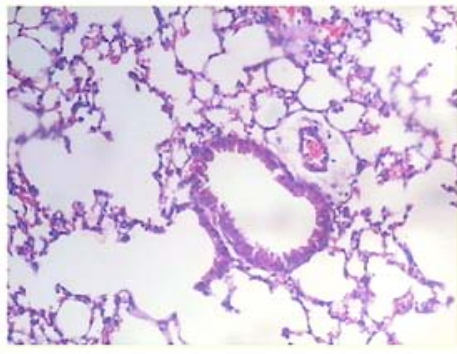

Control 2

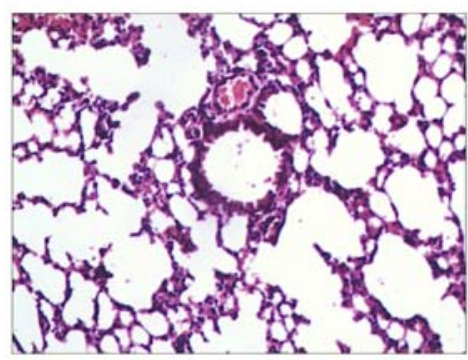

PNU

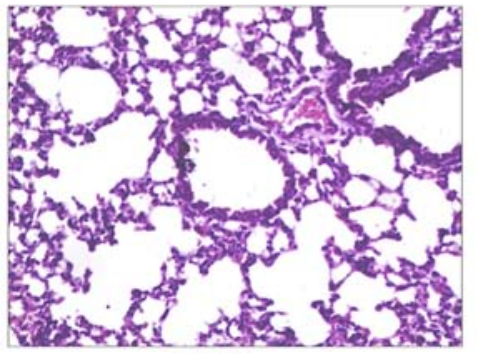

MLA

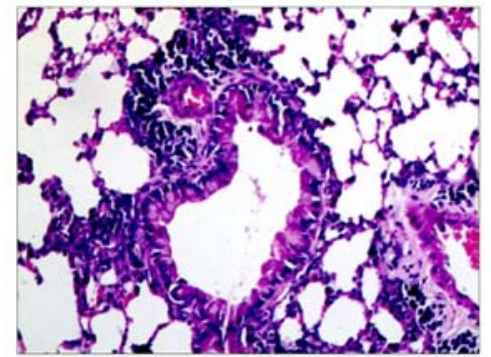

asthma+saline

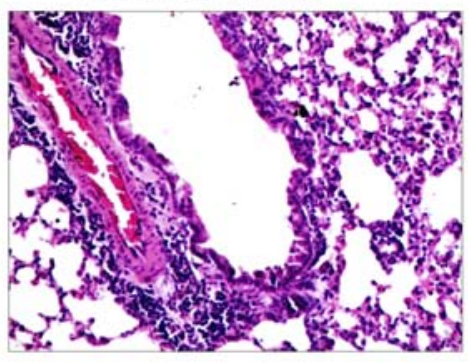

asthma+PNU

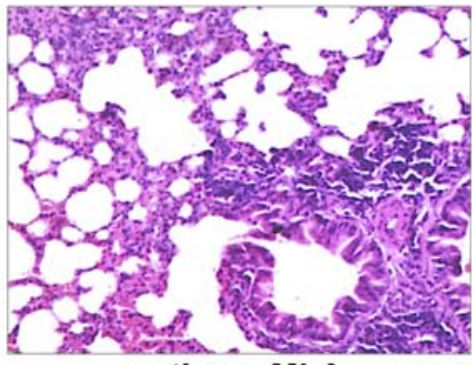

asthma+MLA

Figure 6. Lung inflammatory reactions. The asthma + saline, asthma + MLA, and asthma + PNU groups exhibited considerable muscle thickening, epithelial edema, and inflammatory cell infiltration, and the control 2, PNU and MLA groups showed no obvious inflammation, bronchial smooth muscle thickening, or airway mucus in the lung tissues. Magnification, x100.

We then measured EPI levels in mice in the asthma + saline, asthma + MLA, asthma + PNU, PNU, MLA, and control 2 groups sacrificed at different time-points within $1 \mathrm{~h}$ after treatment according to the different group assignments. As shown in Fig. 7, the concentration of circulating EPI progressively increased in the asthma + PNU group and decreased in the asthma + MLA group relative to levels in the asthma + saline group in a time-dependent manner $(\mathrm{P}<0.05)$. Compared to that in the PNU group, the serum EPI level in the asthma + PNU group was increased by nearly 2 -fold. Similarly, the serum EPI level in the asthma + MLA group was significantly lower than that in the MLA group $(\mathrm{P}<0.05)$. Finally, the serum EPI concentrations in the control 2 and asthma + saline groups were relatively stable.

The RL measurements observed in response to methacholine in each group are shown in Fig. 8. Compared to that in the asthma + saline group, the RL in the asthma + PNU group was significantly reduced upon exposure to the lowest methacholine concentration of $1.526 \mathrm{mg} / \mathrm{ml}$ and for all higher concentrations tested $(\mathrm{P}<0.05)$. As the concentration of methacholine was increased, RL measurements in mice in the asthma + PNU group were reduced by 19.3, 84.1, 92.8 and $218.7 \%$ with exposure to $1.526,3.125,6.25$ and $12.5 \mathrm{mg} / \mathrm{ml}$ methacholine, respectively, compared to the average measurements in the asthma + saline group. Similarly, RL was significantly increased with exposure to increasing concentrations of methacholine in the asthma + MLA group. With exposure to $1.526,3.125,6.25$ and $12.5 \mathrm{mg} / \mathrm{ml}$ methacholine, RL was increased by 53.3, 162.8, 118.3 and $130.8 \%$, respectively, in the asthma + MLA group compared to measurements in the asthma + saline group. RL measurements in the PNU group and MLA group in response to increasing methacholine concentrations did not differ significantly from those in the control 2 group $(\mathrm{P}>0.05)$.

Finally, we evaluated $\alpha 7 \mathrm{nAChR}$ expression in each group, and as shown in Fig. 9A, $\alpha 7 \mathrm{nAChR}$ expression in the asthma + saline, asthma + MLA and asthma + PNU groups was significantly higher than that in the control 2 group. As shown in Fig. 9B and C, we also examined corticosterone levels in each group and did not observe any significant differences $(\mathrm{P}>0.05)$, which indicates that the effects of $\alpha 7 \mathrm{nAChR}$ expression were not mediated by glucocorticoid. In fact, recent studies also confirmed that $\alpha 7 \mathrm{nAChR}$ expression during mouse development is primarily limited to the adrenal medulla (16). Therefore, we next detected the expression of two rate-limiting enzymes involved in EPI synthesis, PNMT and TH, as well as a mediating neuropeptide GAL in each group of mice to rule out the possibility of interference with differences in the levels of EPI synthesis, and the observed expression levels showed no significant differences ( $\mathrm{P}>0.05$; Fig. 9D and $\mathrm{E})$. 


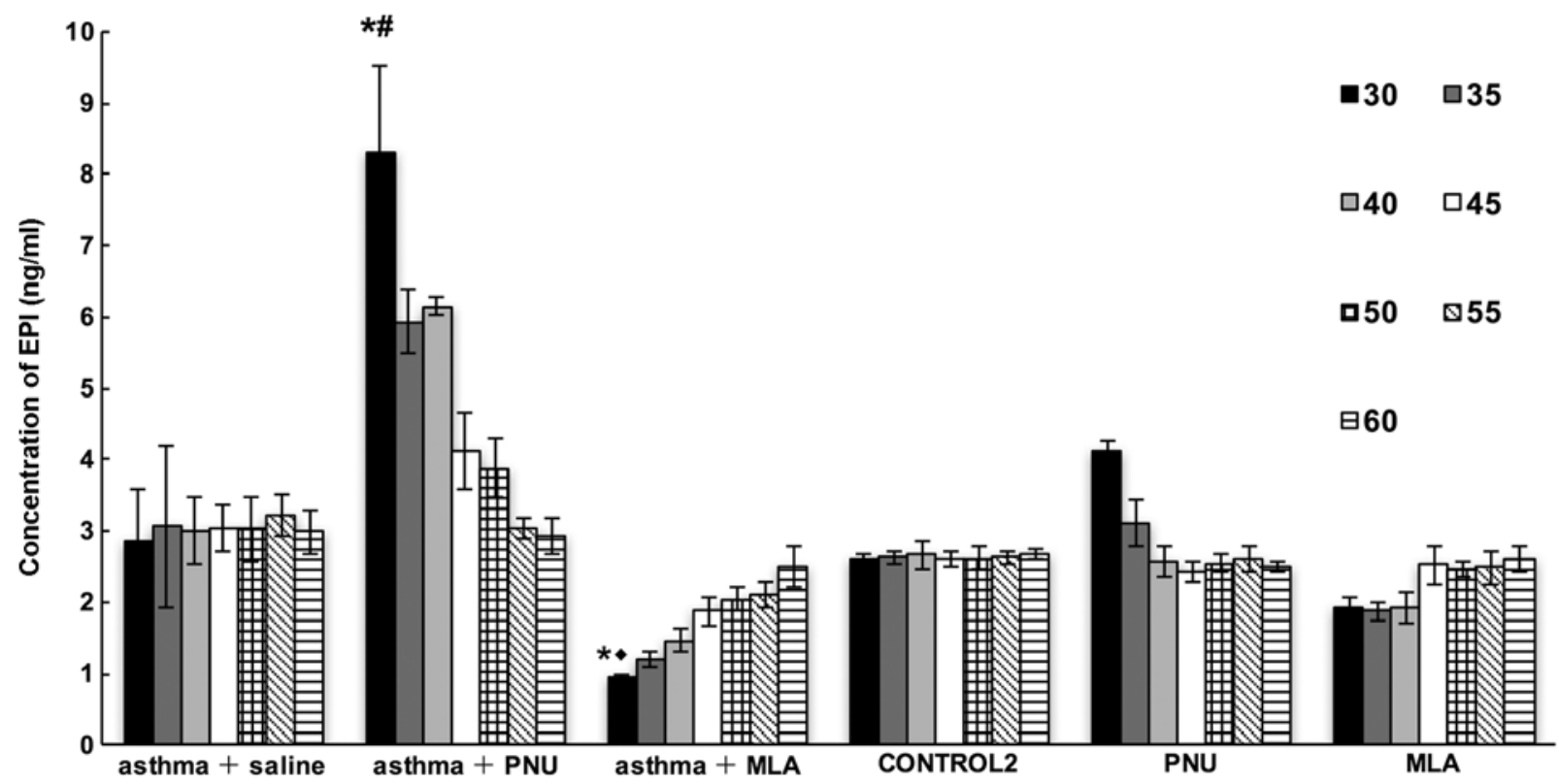

Figure 7. Changes in serum epinephrine (EPI) levels after $\alpha 7 \mathrm{nAChR}$ agonist (PNU) or antagonist (MLA) treatment. The levels of serum EPI in individual mice were measured by ELISA. We sacrificed mice at 30, 35, 40, 45, 50, 55, and $60 \mathrm{~min}$ after treatment and measured their serum EPI levels individually. The concentration of circulating EPI progressively increased in the asthma + PNU group and decreased in the asthma + MLA group relative to levels in the asthma + saline group in a time-dependent manner. Compared to that in the PNU group, the EPI level in the asthma + PNU group was increased by nearly 2-fold. Similarly, the serum EPI level in the asthma + MLA group was significantly lower than that in the MLA group. Data are expressed as the means \pm SD of individual groups ( $\mathrm{n}=5 /$ group). ${ }^{*} \mathrm{P}<0.05$ vs. the asthma + saline group; ${ }^{*} \mathrm{P}<0.05$ vs. the MLA group; ${ }^{\#} \mathrm{P}<0.05$ vs. the $\mathrm{PNU}$ group.

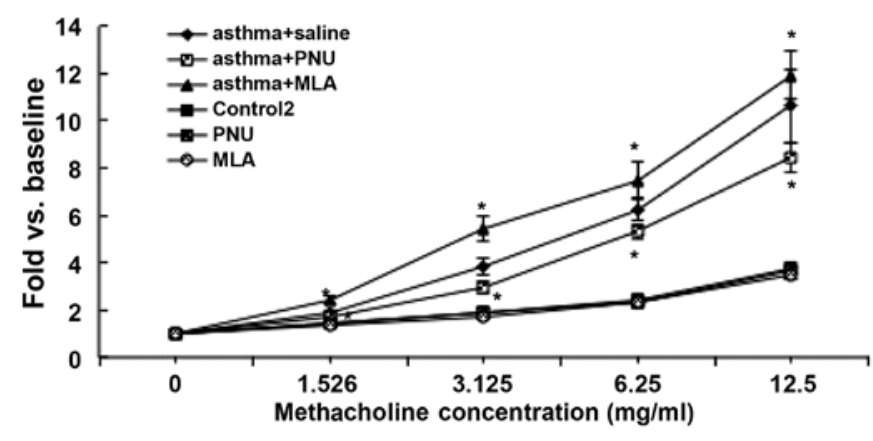

Figure 8. Changes in airway resistance after $\alpha 7 \mathrm{nAChR}$ agonist (PNU) or antagonist (MLA) treatment. Changes in mice airway resistance (RL) in response to increasing concentrations of methacholine $1 \mathrm{~h}$ after last OVA challenge. The airway resistance measurements in mice in the asthma + PNU group were reduced by $19.3,84.1,92.8$ and $218.7 \%$ following exposure to $1.526,3.125,6.25$ and $12.5 \mathrm{mg} / \mathrm{ml}$ methacholine compared to the average measurements in the asthma + saline group. Following exposure to 1.526 , $3.125,6.25$ and $12.5 \mathrm{mg} / \mathrm{ml}$ methacholine, airway resistance was increased by $53.3,162.8,118.3$ and $130.8 \%$, respectively, in the asthma + MLA group compared to measurements in the asthma + saline group. Data are expressed as fold vs. baseline (saline-induced RL) and are shown as the means $\pm \operatorname{SD}(n=5)$. ${ }^{*} \mathrm{P}<0.05$ vs. the asthma + saline group.

\section{Discussion}

The bronchus relies on circulating EPI for dilation due to the lack of adrenergic innervation. Interestingly, EPI levels in asthma patients do not increase as rapidly as needed to alleviate bronchoconstriction $(17,18)$. For this reason, researchers have proposed that this weak increase in circulating EPI is an important factor in the pathogenesis of asthma (19). nAChRs, which are ligand-gated ion channels, have many different subtypes with different calcium permeability, and the flux of $\mathrm{Ca}^{2+}$ is controlled by these receptors on AMCCs, which regulates EPI release. A change in $\alpha 7 \mathrm{nAChR}$ expression has been found in most relevant EPI release experiments.

In the present study, we explored adrenal medulla nAChR subtype redistribution and the impact on circulating levels of EPI in a mouse model of asthma. However, our previous studies have shown that long-term OVA challenge results in increased NGF expression and causes ultrastructural changes, causing EPI synthesis disorders (4,26-28). Therefore, we needed to exclude the impact of reduced synthesis of EPI. We used two methods to eliminate interference of synthesis. i) To reduce AMCC transformation, we used an acute asthmatic model, in which mice received aerosol treatment for a shorter time period; and ii) we established the anti-NGF group to eliminate the transformation effect of NGF using an NGF antibody. Currently, mouse models of asthma can be divided into three types: acute asthma, chronic asthma and severe asthma models. Acute asthma models show significant infiltration of eosinophils and airway hyperresponsiveness as the main feature (20). This model type is used primarily in allergic disease studies $(21,22)$. Models of chronic asthma, which are mainly used for airway remodeling research, exhibit smooth muscle cell proliferation, epithelial thickening, goblet cell metaplasia, and mild fibrosis $(23,24)$. Severe asthma models are characterized by infiltration of a large number of eosinophils and extensive neutrophils. Significant airway wall thickening, airway smooth muscle layer thickening, and reticular basement membrane thickening also are observed (25). This model type is usually employed in severe asthma research. In the present study, there were no obvious differences in epithelial edema and inflammatory cell infiltration between the asthma group and the asthma + anti-NGF group. Therefore, there was 

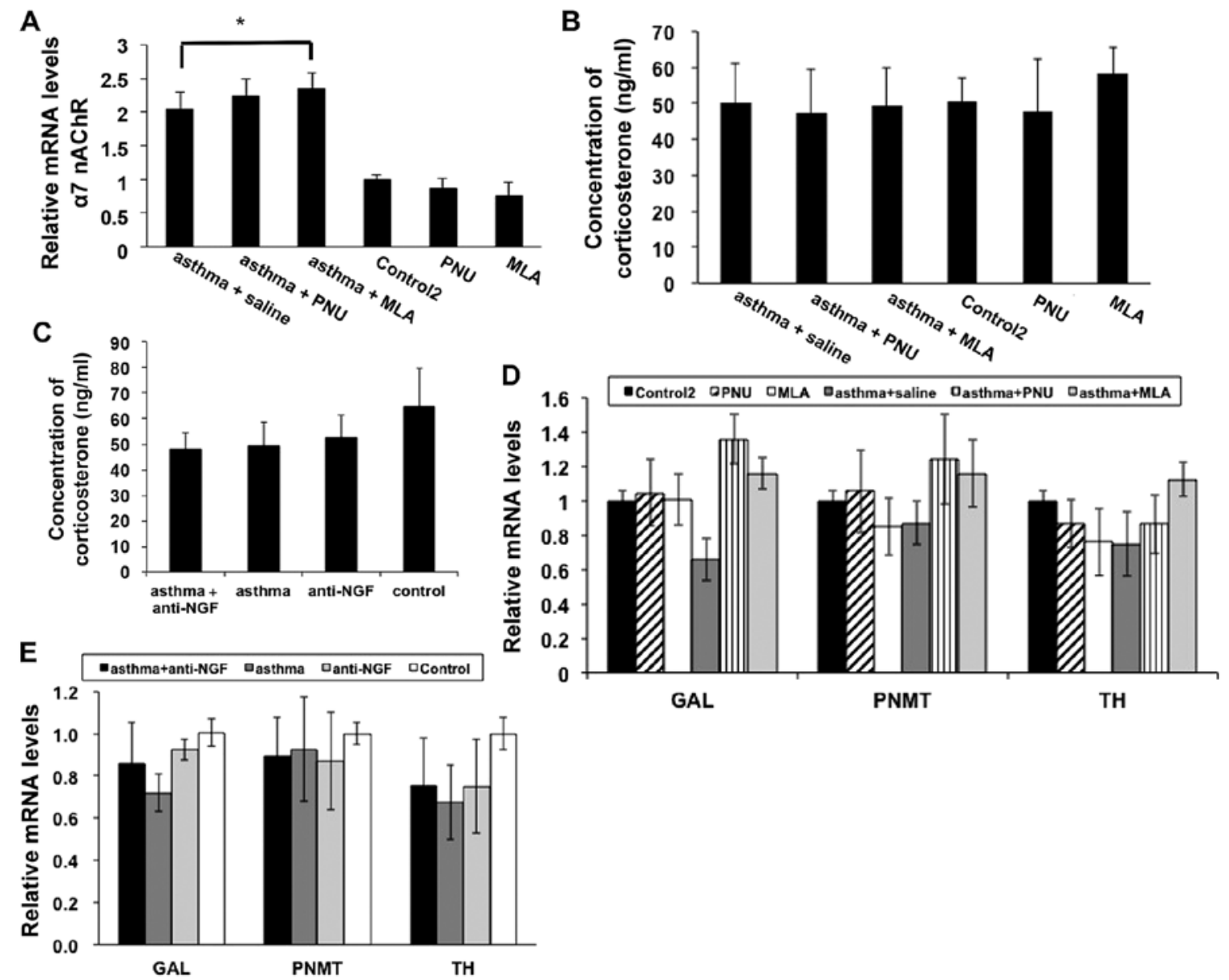

GAL

PNMT

TH

Figure 9. $\alpha 7$ nicotinic acetylcholine receptor (nAChR), phenylethanolamine N-methyltransferase (PNMT), tyrosine hydroxylase (TH), and galanin (GAL) expression and serum levels of corticosterone. (A) Relative $\alpha 7 \mathrm{nAChR}$ mRNA expression in the adrenal medulla of individual mice. $\alpha 7 \mathrm{nAChR}$ expression levels in the asthma + saline, asthma + MLA, and asthma + PNU groups were significantly higher than that in the control 2 group. (B and C) There was no difference in serum levels of corticosterone between each group and the control 2 group (B), or between each group and the control group (C). (D and E) PNMT, TH and GAL mRNA expression in individual mice, showing no significant differences between groups. Data are expressed as the means \pm SD for the individual groups ( $\mathrm{n}=5$ /group). ${ }^{*} \mathrm{P}<0.05$ vs. the control 2 group.

no significant difference in pulmonary inflammation between the asthma group and the asthma + anti-NGF group. Thus, we eliminated the interference of EPI synthesis disorders.

EPI release is controlled by $\mathrm{nAChRs}$ that consist of a series of different subtypes with different ion permeability in the adrenal medulla. The distributions of these subtypes regulate the ion permeability and the capability for EPI release. Studies have shown that many factors can increase the expression of $\alpha 7 \mathrm{nAChR}$ in PC12 cells, including nicotine, hypoxia, and NGF in a time- and dose-dependent manner (9-11). $\alpha 7 \mathrm{nAChR}$ has received increasing attention in recent years, because $\alpha 7 \mathrm{nAChR}$ generally forms a single homologous subunit pentamer, and $\alpha 7 \mathrm{nAChR}$ has the highest $\mathrm{Ca}^{2+}$ permeability among all nAChRs (13). In this study, we found that obvious $\mathrm{nAChR}$ subtype redistribution occured in the acute asthma mouse model, and $\alpha 7 \mathrm{nAChR}$ subtype expression was significantly increased by up to $260 \%$. In addition, the expression of $\alpha 3, \alpha 4$, and $\beta 4$ subunits was relatively increased by 69 , 66 and $39 \%$, respectively. However, subunits containing the $\alpha 3-6$ and $\beta$ subunits tend to constitute heteromeric receptors, which have a fractional $\mathrm{Ca}^{2+}$ current (13). Therefore, based on previous studies and our findings, we believe that the changes in the $\alpha 7 \mathrm{nAChR}$ subtype play a primary role in promoting
EPI release in response to asthma symptoms. $\alpha 7 \mathrm{nAChR}$ has become a hot topic in recent years, but primarily with a focus on the brain $\alpha 7 \mathrm{nAChR}$. For example, Morioka et al found that $\alpha 7 \mathrm{nAChR}$ can be activated to increase the expression of excitatory amino acid transporter 1 , which may be useful for the treatment of neurological disorders associated with disturbance of the glutamatergic system (29). O'Neill et al found that $\alpha 7 \mathrm{nAChR}$ can improve cognitive function in animal models of Alzheimer's disease (30,31). In addition, $\alpha 7 \mathrm{nAChR}$ activation also has been shown to reduce stroke damage by reducing oxidative stress as well as via a neuron protective effect in Parkinson's disease (32). However, little is known about the function of $\alpha 7 \mathrm{nAChR}$ in asthma, and for the first time, our study showed that $\alpha 7 \mathrm{nAChR}$ expression was significantly increased in asthmatic mice. This increase in $\alpha 7 \mathrm{nAChR}$ expression in asthmatic mice significantly promotes flow of calcium ions and release of EPI.

To further test the effect of the $\alpha 7 \mathrm{nAChR}$ subtype in EPI release function, we treated mice with PNU ( $\alpha 7 \mathrm{nAChR}$ agonist) or MLA ( $\alpha 7 \mathrm{nAChR}$ antagonist) at $30 \mathrm{~min}$ after the last aerosol treatment and detected EPI levels 30 min later. We tested lung function in each mouse at $1 \mathrm{~h}$ after the last treatment. PNU and MLA cannot influence the adrenal 
gland through the central nervous system as these molecules cannot pass the blood-brain barrier (33). Therefore, adrenal $\alpha 7 \mathrm{nAChR}$ expression directly affects the level of serum EPI. The levels of EPI were significantly increased after application of PNU, an $\alpha 7 \mathrm{nAChR}$ agonist, in the asthmatic mice (asthma PNU interference group). On the one hand, EPI levels were increased by $\sim 2$-fold compared to levels in the asthma saline treatment group at 30 min after treatment with PNU and then gradually decreased until reaching the same level as in the asthma saline treatment group at 55 min after PNU treatment. On the other hand, pulmonary function tests showed that RL in the asthma PNU interference group was significantly reduced by up to $218.7 \%$. The EPI level in the MLA asthma intervention group markedly declined by $\sim 50 \%$ compared to the level in the asthma saline treatment group and then gradually decreased until reaching the same level in the asthma saline treatment group at 55 min after MLA treatment. The RL in the asthma MLA interference group was significantly increased by up to $162.8 \%$. Because $\alpha 7 \mathrm{nAChR}$ subtype expression increased by more than $200 \%$, the $\alpha 7 \mathrm{nAChR}$ subtype counteracted the increased EPI level after PNU treatment and caused a more than $200 \%$ decrease in $\mathrm{RL}$ in the mice. Similarly, due to increased expression of $\alpha 7$ $\mathrm{nAChR}$, the $\alpha 7 \mathrm{nAChR}$ antagonist MLA resulted in a significant decrease in the EPI level and $150 \%$ increase in the RL. In conclusion, we found that an increase in $\alpha 7 \mathrm{nAChR}$ may facilitate the release of more EPI by AMCCs and an increase in the EPI level could relieve RL.

Glucocorticoid can increase circulating EPI concentrations, and glucocorticoid has a potent anti-inflammatory effect. Thus, it can produce a therapeutic effect in asthma. Therefore, we examined the serum levels of glucocorticoid, and similar results were observed between each group. These findings indicate that overexpression of $\alpha 7 \mathrm{nAChR}$ is not caused by glucocorticoid. Recent studies have also indicated that during mouse development, $\alpha 7 \mathrm{nAChR}$ is basically expressed in the adrenal medulla, whereas the adrenal cortex shows slight expression of $\alpha 7 \mathrm{nAChR}$ (16). Therefore, this study showed that the nicotinic acetylcholine subtype redistribution in a mouse model of acute asthma indeed occurs, and the main subtype increased is $\alpha 7 \mathrm{nAChR}$. EPI release in the asthmatic mice was significantly increased after $\alpha 7 \mathrm{nAChR}$ agonist treatment and the ability to deal with methacholine stimulation was significantly enhanced. Moreover, we measured PNMT and TH, which are two rate-limiting enzymes of EPI synthesis, and an important neuromedin GAL in mice of all groups $(14,15)$. The results showed that the level of EPI synthesis was not affected, indicating that the mice did not have an EPI synthesis disorder.

In conclusion, the present study demonstrates that the redistribution of $\mathrm{nAChR}$ subtypes, primarily $\alpha 7 \mathrm{nAChR}$ occurs in the adrenal medulla in asthmatic mice. Increased $\alpha 7 \mathrm{nAChR}$ expression can rapidly increase serum EPI levels and decrease airway responsiveness.

\section{Acknowledgements}

This study was funded by the National Natural Science Foundation of China (no. 81370127) and the Fundamental Research Funds for the Central Universities of Central South University (no. 2013zzts315).

\section{References}

1. Barnes PJ, Brown MJ, Silverman M and Dollery CT: Circulating catecholamines in exercise and hyperventilation induced asthma. Thorax 36: 435-440, 1981.

2. Ind PW, Causon RC, Brown MJ and Barnes PJ: Circulating catecholamines in acute asthma. Br Med J (Clin Res Ed) 290: 267-269, 1985.

3. Wang J, Hu CP and Feng JT: Dysfunction of releasing adrenaline in asthmatic adrenaline medullary chromaffin cells due to functional redundancy primed by nerve growth factor. Zhonghua Jie $\mathrm{He} \mathrm{He} \mathrm{Hu}$ Xi Za Zhi 29: 812-815, 2006 (In Chinese).

4. Feng JT and Hu CP: Dysfunction of releasing adrenaline in asthma by nerve growth factor. Med Hypotheses 65: 1043-1046, 2005.

5. Yamaguchi-Shima N, Okada S, Shimizu T, Usui D, Nakamura K, Lu L and Yokotani K: Adrenal adrenaline- and noradrenaline-containing cells and celiac sympathetic ganglia are differentially controlled by centrally administered corticotropin-releasing factor and arginine-vasopressin in rats. Eur J Pharmacol 564: 94-102, 2007.

6. Fenster CP, Rains MF, Noerager B, Quick MW and Lester RA: Influence of subunit composition on desensitization of neuronal acetylcholine receptors at low concentrations of nicotine. J Neurosci 17: 5747-5759, 1997.

7. Fucile $\mathrm{S}: \mathrm{Ca}^{2+}$ permeability of nicotinic acetylcholine receptors Cell Calcium 35: 1-8, 2004.

8. Nai Q, McIntosh JM and Margiotta JF: Relating neuronal nicotinic acetylcholine receptor subtypes defined by subunit composition and channel function. Mol Pharmacol 63: 311-324, 2003.

9. Takahashi T, Yamashita H, Nakamura S, Ishiguro H, Nagatsu T and Kawakami H: Effects of nerve growth factor and nicotine on the expression of nicotinic acetylcholine receptor subunits in PC12 cells. Neurosci Res 35: 175-181, 1999.

10. Shin MK, Han W, Bevans-Fonti S, Jun JC, Punjabi NM and Polotsky VY: The effect of adrenal medullectomy on metabolic responses to chronic intermittent hypoxia. Respir Physiol Neurobiol 203: 60-67, 2014

11. Utsugisawa K, Nagane Y, Obara D and Tohgi H: Increased expression of alpha7 nAChR after transient hypoxia in PC12 cells. Neuroreport 11: 2209-2212, 2000.

12. Rogers SW, Mandelzys A, Deneris ES, Cooper E and Heinemann S: The expression of nicotinic acetylcholine receptors by PC12 cells treated with NGF. J Neurosci 12: 4611-4623, 1992.

13. Dajas-Bailador F and Wonnacott S: Nicotinic acetylcholine receptors and the regulation of neuronal signalling. Trends Pharmacol Sci 25: 317-324, 2004.

14. Fischer-Colbrie R, Eskay RL, Eiden LE and Maas D: Transsynaptic regulation of galanin, neurotensin, and substance $P$ in the adrenal medulla: combinatorial control by second-messenger signaling pathways. J Neurochem 59: 780-783, 1992.

15. Fischer-Colbrie R, Iacangelo A and Eiden LE: Neural and humoral factors separately regulate neuropeptide $\mathrm{Y}$, enkephalin, and chromogranin A and B mRNA levels in rat adrenal medulla. Proc Natl Acad Sci USA 85: 3240-3244, 1988.

16. Gahring LC, Myers E, Palumbos S and Rogers SW: Nicotinic receptor alpha7 expression during mouse adrenal gland development. PLoS One 9: e103861, 2014.

17. Barnes P, FitzGerald G, Brown M and Dollery C: Nocturnal asthma and changes in circulating epinephrine, histamine, and cortisol. N Engl J Med 303: 263-267, 1980.

18. van Aalderen WM, Postma DS, Koëter GH and Knol K: Nocturnal airflow obstruction, histamine, and the autonomic central nervous system in children with allergic asthma. Thorax 46: 366-371, 1991

19. Bates ME, Clayton M, Calhoun W, Jarjour N, Schrader L, Geiger K, Schultz T, Sedgwick J, Swenson C and Busse W: Relationship of plasma epinephrine and circulating eosinophils to nocturnal asthma. Am J Respir Crit Care Med 149: 667-672, 1994.

20. Bates JH, Rincon M and Irvin CG: Animal models of asthma. Am J Physiol Lung Cell Mol Physiol 297: L401-L410, 2009.

21. Reddy AT, Lakshmi SP and Reddy RC: Murine model of allergen induced asthma. J Vis Exp 63: e3771, 2012.

22. Secor ER, Carson WF, Singh A, Pensa M, Guernsey LA, Schramm CM and Thrall RS: Oral bromelain attenuates inflammation in an ovalbumin-induced murine model of asthma. Evid Based Complement Alternat Med 5: 61-69, 2008.

23. Ahn JH, Kim CH, Kim YH, Kim SJ, Lee SY, Kim YK, Kim KH, Moon HS, Song JS, Park SH, et al: Inflammatory and remodeling events in asthma with chronic exposure to house dust mites: a murine model. J Korean Med Sci 22: 1026-1033, 2007. 
24. Johnson JR Jr, Wiley RE, Fattouh R, Swirski FK, Gajewska BU, Coyle AJ, Gutierrez-Ramos JC, Ellis R, Inman MD and Jordana M: Continuous exposure to house dust mite elicits chronic airway inflammation and structural remodeling. Am J Respir Crit Care Med 169: 378-385, 2004.

25. Jiang XB, Zhu Y and Yin KS: Reproduction of severe asthma model in mice. Zhongguo Wei Zhong Bing Ji Jiu Yi Xue 18: 733-736, 2006 (In Chinese).

26. Hu CP, Zou YQ, Feng JT and Li XZ: The effect of unilateral adrenalectomy on transformation of adrenal medullary chromaffin cells in vivo: a potential mechanism of asthma pathogenesis. PLoS One 7: e44586, 2012.

27. Hu CP, Zou JT, Zou YQ, Li XZ and Feng JT: Kidney-tonifying recipe can repair alterations in adrenal medullary chromaffin cells in asthmatic rats. Evid Based Complement Alternat Med 2012: 542621, 2012.

28. Feng JT, Wu XM, Li XZ, Zou YQ, Qin L and Hu CP: Transformation of adrenal medullary chromaffin cells increases asthmatic susceptibility in pups from allergen-sensitized rats. Respir Res 13: 99, 2012

29. Morioka N, Tokuhara M, Nakamura Y, Idenoshita Y, Harano S, Zhang FF, Hisaoka-Nakashima K and Nakata Y: Primary cultures of rat cortical microglia treated with nicotine increases in the expression of excitatory amino acid transporter 1 (GLAST) via the activation of the $\alpha 7$ nicotinic acetylcholine receptor. Neuroscience 258: 374-384, 2014.
30. O'Neill MJ, Murray TK, Lakics V, Visanji NP and Duty S: The role of neuronal nicotinic acetylcholine receptors in acute and chronic neurodegeneration. Curr Drug Targets CNS Neurol Disord 1: 399-411, 2002.

31. VicensP,Ribes D,HerediaL, Torrente Mand Domingo JL:Effects of an alpha7 nicotinic receptor agonist and stress on spatial memory in an animal model of Alzheimer's disease. Biomed Res Int 2013: 952719, 2013.

32. Han Z, Shen F, He Y, Degos V, Camus M, Maze M, Young WL and $\mathrm{Su} \mathrm{H}$ : Correction: activation of $\alpha-7$ nicotinic acetylcholine receptor reduces ischemic stroke injury through reduction of pro-inflammatory macrophages and oxidative stress. PLoS One 11: e0152218, 2016

33. Bodnar AL, Cortes-Burgos LA, Cook KK, Dinh DM, Groppi VE, Hajos M, Higdon NR, Hoffmann WE, Hurst RS, Myers JK, et al: Discovery and structure-activity relationship of quinuclidine benzamides as agonists of alpha7 nicotinic acetylcholine receptors. J Med Chem 48: 905-908, 2005. 